\title{
Blindness in the eastern Mediterranean countries
}

\author{
Khalid F Tabbara
}

Blinding eye diseases remain a highly prevalent and serious health problem in many developing countries. The exact number of blind individuals is not known. It is estimated that there are 38 million people who have visual impairment and are at risk of becoming blind. ${ }^{12}$

The prevalence of blindness in developing countries is 10-40 times higher than in developed countries and close to three quarters of the world's blindness is either curable or preventable. The majority of blind people on earth reside in the developing nations of Africa, Asia, and Latin America.

The World Health Organization (WHO) definition of blindness is a visual acuity of less than $3 / 60(20 / 200,0.05)$, and low vision is less than $6 / 18(20 / 50,0.3)$ in the better eye with the best correction. ${ }^{1}$ In the eastern Mediterranean countries $^{2}$ (Table 1), there are several studies on the prevalence of blindness..$^{3-14}$ Certain studies were community based prevalence surveys while others included reports on blindness from registries of schools for the blind. The prevalence of blindness in Lebanon is $0.6 \%{ }^{8}$ and $1.5 \%$ in Saudi Arabia. ${ }^{12}$ The leading causes of blindness have been determined by information retrieved from registries for the blind in a number of countries. In general, data obtained from hospitals, social security records, or institutions for the blind may give us an idea about the causes of blindness but these sources suffer from certain limitations.

Accepted for publication 28 March 2001

Table 1 Demography of eastern Mediterranean countries

\begin{tabular}{|c|c|c|c|}
\hline Country & $\begin{array}{l}\text { Total population } \\
(\times 1000)\end{array}$ & Year & Urban population (\%) \\
\hline Afghanistan & 20452000 & 1996 & 25 \\
\hline Bahrain & 623000 & 1997 & 59 \\
\hline Cyprus & 655000 & 1997 & 69 \\
\hline Djibouti & 670000 & 1997 & 76 \\
\hline Egypt & 61880000 & 1998 & 47 \\
\hline Iran (Islamic Republic of) & 61505000 & 1998 & 61 \\
\hline Iraq & 21847000 & 1997 & 71 \\
\hline Jordan & 4732000 & 1998 & 80 \\
\hline Kuwait & 1809000 & 1997 & 100 \\
\hline Lebanon & 3700000 & 1997 & 85 \\
\hline Libyan Arab Jamahiriya & 4654000 & 1997 & 85 \\
\hline Morocco & 27775000 & 1998 & 53 \\
\hline Oman & 2302000 & 1998 & 74 \\
\hline Pakistan & 139020000 & 1995 & 32 \\
\hline Palestine & 2893000 & 1998 & 46 \\
\hline Qatar & 693000 & 1995 & 100 \\
\hline Saudi Arabia & 15655000 & 1997 & 80 \\
\hline Somalia & 6602000 & 1996 & 28 \\
\hline Sudan & $31326000^{\star}$ & 1999 & 33 \\
\hline Syrian Arab Republic & 15597000 & 1998 & 50 \\
\hline Tunisia & 9333000 & 1998 & 61 \\
\hline United Arab Emirates & 2624000 & 1997 & 79 \\
\hline Yemen (Republic of) & 16933000 & 1997 & 24 \\
\hline Total & 455087000 & & \\
\hline
\end{tabular}

^Estimate.

Source: World Health Organization (WHO).
Often excluded from consideration are remote populations, those who do not seek medical advice, unilateral blindness, older individuals, and preschool children.

In countries in the eastern Mediterranean eye diseases have long been recognised as a major health problem. Table 2 shows the leading causes of blindness in these countries. In Saudi Arabia, a community based blindness survey was conducted to determine the prevalence of blindness and visual impairment and to assess the prevalence of the major causes of blinding eye disease. ${ }^{12}{ }^{13} \mathrm{~A}$ nationwide random stratified, multistage cluster sample was included in the survey. This survey revealed that $1.5 \%$ of the population are blind and another $7.8 \%$ are visually impaired according to the WHO definition of blindness. ${ }^{12}$ The most common causes of blindness in Saudi Arabia were cataract, trachoma, non-trachomatous corneal scars, refractive errors, congenital anomalies, failed medical or surgical treatment, and glaucoma. On the other hand, refractive errors, amblyopia, and trauma were causes of unilateral loss of vision. About $7 \%$ of all Saudi Arabians and $42 \%$ of those older than 40 years developed cataract and over $3.5 \%$ of the population had corneal scars; about half were caused by trachoma. The data presented have demonstrated that eye disease and blindness are important health problems in Saudi Arabia. Over $1.5 \%$ of the total population and over $20 \%$ of the population older than 60 years of age were blind. ${ }^{8}$ The prevalence of blindness reflects the current and previous status of eye diseases. Recent socioeconomic development in Saudi Arabia and other Arab Gulf countries has greatly influenced the causation of blindness in these countries. For example, the prevalence of trachoma has decreased dramatically over the past two decades. ${ }^{15}$ Currently, in urban communities there are practically no cases of active trachoma. This socioeconomic development is less pronounced in other eastern Mediterranean countries.

\section{Causes of blindness}

CATARACT

Cataract accounts for half of the blindness despite the fact that the condition is generally curable. The rate of surgery in eastern Mediterranean countries remains low. The provision of widespread cataract surgery delivered in a timely fashion before individuals are visually impaired by this condition may prevent major reduction of blindness and visual loss. A 
Table 2 Estimation of prevalence and causes of blindness in eastern Mediterranean countries ${ }^{t}$

\begin{tabular}{lcc}
\hline & No of individuals & $\%$ \\
\hline Population & 455087000 & 100 \\
No of blind & 3185609 & 0.7 \\
Low vision & 20478915 & 4.5 \\
\hline Causes of blindness & No of blind & $\%$ \\
\hline Cataract & 1439895 & 45.2 \\
Trachoma & 818702 & 25.7 \\
Glaucoma & 181580 & 5.7 \\
Other & 745432 & $\mathbf{1 0 0}$ \\
\hline Total & $\mathbf{3} \mathbf{1 8 5} \mathbf{6 0 9}$ & \\
\hline
\end{tabular}

${ }^{\star}$ Blindness is visual acuity of less than 3/60 (0.05) or corresponding visual fields loss in the better eye (loss of navigation vision).

tLow vision is visual acuity of less than $6 / 18(0.3)$ but equal or better than $3 / 60$ in the better eye with best correction.

$\ddagger$ Other causes include errors of refraction, diabetic retinopathy, age related macular degeneration, optic atrophy, trauma, failed medical or surgical treatment, and others.

related disturbing issue is the frequency with which ophthalmic surgery results in intraoperative or postoperative complications. In several eastern Mediterranean countries, the rate of complications following cataract surgery remains high. Approximately $4 \%$ of all blindness in Saudi Arabia was found to be iatrogenic - that is, caused by failed medical or surgical therapy. ${ }^{12}$ Since the survey was a prevalence survey and not an incidence survey, such complications may represent the previous status of ophthalmic care in Saudi Arabia. The recent introduction of new techniques for cataract surgery, including phacoemulsification, has been started by ophthalmologists in eastern Mediterranean countries. Despite these advances, less than $20 \%$ of the cataract surgery in eastern Mediterranean countries is phacoemulsification. This is because of lack of resources in certain areas, the presence of corneal scars, and advanced mature cataracts. This highlights the necessity of adequate recruitment, training, and transfer of technology and skills to surgeons working in this region.

\section{TRACHOMA}

Trachoma is uncommon in Lebanon, Syria, and Jordan but is still highly prevalent in the rural communities of Iraq, Saudi Arabia, United Arab Emirates, Qatar, and Oman. Trachoma remains an important cause of blindness and the leading preventable cause of visual disability. Data from several surveys have indicated that trachoma is rapidly waning as a highly endemic disease. The complications of trachoma appear during adulthood. The prevention of blindness and visual impairment from the disease remains a critical issue. Conjunctival scarring with lid deformities and trichiasis leads to major ocular surface complications and corneal scarring. Recognition and referral by local health workers of patients with entropion and trichiasis, especially those with lingering inflammatory trachoma, or their exposed family members are priorities in this context for prevention of blindness.

CORNEAL SCARS

Corneal scars from trauma, infection, or failed medical intervention are also preventable and mostly curable causes of visual loss. The difference between the preservation of vision and a poor visual outcome in these conditions is prompt and skilful management. It is unfortunate to realise that eye banks are available in only a small number of cities in the eastern Mediterranean countries making corneal transplantation a rare procedure because of lack of corneal tissue.

\section{REFRACTIVE ERRORS}

Refractive errors are among the leading causes of visual loss in the eastern Mediterranean countries. The visual impairment due to refractive errors can be improved by wearing spectacles in the vast majority of cases. In eastern Mediterranean countries, however, individuals are reluctant to wear spectacles. The use of contact lenses has contributed to an increase in the incidence of infectious keratitis. New surgical intervention techniques such as photorefractive keratectomy (PRK), radial keratotomy (RK), and laser in situ keratomileusis (LASIK) have been adopted in certain cities in the Middle East. The learning curve of ophthalmologists, however, may have caused certain complications. Complications associated with flap production in LASIK have led to serious complications and corneal scars and visual loss. Infectious keratitis following these procedures has been reported. The transfer of skills and technology to developing countries is sometimes poorly organised. ${ }^{1}$ The rapid development of new instrumentation, new techniques, and new pharmaceuticals has led to serious iatrogenic blindness in many eastern Mediterranean countries. The transfer of technology and skills has not been properly cultivated. The rapid transfer without proper training of doctors has led to serious ocular complications and visual loss.

"OVER THE COUNTER" TOPICAL MEDICATIONS The "over the counter" sale of topical medications such as steroids has led to the loss of vision secondary to steroid induced cataracts and glaucoma. Topical anaesthetic corneal complications are also seen in many individuals because of the misuse of topical anaesthetic eye drops. ${ }^{16}$ Folk remedies and homemade eyedrop preparations have also led to serious ocular surface complications leading to blindness. ${ }^{17}{ }^{18}$ In rural areas of the Middle East, one may still find homemade remedies and folk medicine that may also lead to loss of vision.

OTHER CAUSES OF BLINDNESS

Certain ocular conditions that are seen in Western countries, such as macular degeneration, remain less common in the eastern Mediterranean countries. There are many factors that may contribute to the low prevalence of macular degeneration. The lifespan of individuals living in eastern Mediterranean countries is still less than that of those living in the United States and Europe and, therefore, the prevalence of age related macular degeneration may not be as high as in western countries. Early onset of cataract may prevent light 
Table 3 Causes of bilateral blindness among children in eastern Mediterranean countries

1 Retinal degeneration
2 Congenital cataract
3 Congenital glaucoma
4 Corneal scars
5 Others: vitamin A deficiency, trauma, optic atrophy, etc

related damage of the macula. The retinal pigment epithelium of dark skinned individuals may protect against macular damage. The incidence of macular degeneration is known to be significantly less in black than in white people.

Other important causes of blindness are diabetic retinopathy and glaucoma. The socioeconomic development in the eastern Mediterranean countries has led to an acute rise in the incidence of diabetes mellitus. Individuals in these countries for many years had limited intake of sugars and carbohydrates, which may have led to the evolution of a thrifty gene. Sudden change in their dietary habits may have led to hyperglycaemia. The complications of diabetes including diabetic retinopathy have increased dramatically in the past two decades.

Glaucoma remains an important cause of blindness in the eastern Mediterranean countries. Delay in the presentation of patients with ocular hypertension and glaucoma has led to blindness in many countries. In Saudi Arabia, glaucoma was responsible for blindness among $3 \%$ of the population above the age of 40 years. Glaucoma is one of the leading causes of blindness and produces irreversible visual damage. Open angle glaucoma is called "the little thief" in Saudi Arabia because blindness may occur despite the lack of symptoms. Painless progressive loss of vision may not be noted by the patient until vision is seriously decreased. Screening programmes and public education are highly desirable for the prevention of blindness from glaucoma. Training programmes should be developed for doctors and other health personnel working in primary health care. Measurements of the intraocular pressure should be a part of the routine physical examination. Diagnostic equipment such as tonometers and ophthalmoscopes should be provided to all health centres. Effective and simple tonometers can be made available. Education of the public about glaucoma, particularly with emphasis on its types and symptoms and its relation to age and genetic factors, is imperative. People who are above the age of 35 years, especially those with family history of glaucoma, should have ophthalmic examination and tonometry.

\section{Childhood blindness}

Several reports on childhood blindness in eastern Mediterranean countries have appeared in the literature over the past two decades. The major causes of blindness in children are shown in Table 3. In general, genetic causation of childhood blindness is frequent in developed countries, whereas nutritional and infectious factors are more common causes of childhood blindness in developing countries. In many eastern Mediterranean countries, however, the causes of childhood blindness are changing.
Table 4 Guidelines for the prevention of childhood blindness $^{6-9}$

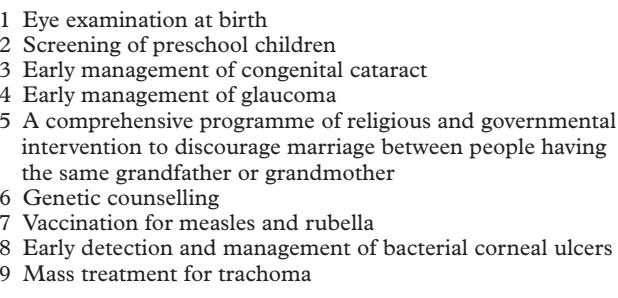

Tabbara and Badr ${ }^{6}$ studied the causes of childhood blindness in individuals born before 1962 and those born after 1962 in Saudi Arabia. They found that in individuals born before 1962 acquired diseases led to blindness in 75\% of the patients. On the other hand, in individuals born from 1962 onwards, genetically determined diseases accounted for $84 \%$ of childhood blindness. Furthermore, $66 \%$ of this group were the product of consanguineous marriages. Subsequent studies in other eastern Mediterranean countries such as Lebanon and Jordan showed a similar trend in childhood blindness. ${ }^{78}$ Data obtained from these studies indicate a shift in the causes of childhood blindness from acquired causes to genetically determined causes. After 1962, no smallpox keratitis leading to blindness was detected in eastern Mediterranean countries. This is the result of the WHO sponsored mass vaccination which eradicated smallpox. In addition, there was a corresponding decrease in the incidence of bacterial corneal ulcers. This could be related to a marked decrease in the incidence of measles with the adoption of vaccination. Bacterial keratitis may complicate the course of measles keratitis. Measles vaccination could lead to a decrease in corneal complications following measles.

Blinding infectious diseases have decreased over the past decades. This decrease in acquired causes of childhood blindness has revealed a relative increase in the incidence of genetically determined causes of blindness. The incidence of parental consanguinity among blind children with genetic diseases was significantly higher than among children in the group with acquired diseases. Consanguineous marriage is a common and accepted tradition in eastern Mediterranean countries. Marriages among cousins are common and encouraged by many families. Table 4 shows the guidelines for the prevention of childhood blindness in these countries.

Considering unilateral causes of blindness, trauma remains the most important factor. This is followed by congenital anomalies, unilateral cataract, amblyopia, corneal opacities, and iatrogenic factors.

\section{Prevention of blindness}

Prevention of blindness in eastern Mediterranean countries requires major commitment and efforts from governmental agencies, private organisations, and individuals. Public education remains an important factor in the prevention and avoidance of many causes that 
lead to blindness. Public education about the dangers of consanguineous marriages especially in cases of autosomal recessive disorders that lead to blindness and screening for glaucoma and diabetic retinopathy are high priorities. Mass vaccination in childhood against classic infections such as measles, mumps, rubella, Haemophilus, and diphtheria would help in preventing corneal infections. Public education for the early management of ocular surface infections and corneal ulcers would also help in the prevention of acquired causes of blindness. Common predisposing factors for corneal infections are the use and abuse of cosmetic coloured contact lenses and optical corrective soft contact lenses. Extended wear soft contact lenses have been associated with a significant rise in infectious keratitis. ${ }^{19}$ The turmoil in the Middle East may also contribute to the high numbers with loss of vision from blast and shrapnel injuries. ${ }^{20}$ Search for peace in the region should be a high priority for the prevention of these injuries. Screening programmes may have to be considered for the early detection of trachoma among schoolchildren in rural communities and for glaucoma after the age of 30 .

Public education should also address the use and misuse of topical medications without ophthalmic surveillance. The wide topical use of corticosteroids has led to steroid induced glaucoma and cataract in patients with vernal keratoconjunctivitis. ${ }^{21}$ Continuing medical education programmes should be organised for the prevention of blindness. Establishing new structured postgraduate training programmes in ophthalmology is highly desirable and badly needed in many countries. Traditional healing methods may have to be abandoned and this requires good public education. Eye banks should be established in every country to provide corneal tissue for corneal transplantation. Genetic counselling may be effective in decreasing the incidence of certain disorders that lead to blindness. Newly discovered molecular technology may help in the early detection of genetically determined blinding diseases. Furthermore, blindness due to congenital glaucoma, which is a common cause of blindness in childhood, can be reduced by educational campaigns and early management. Rubella vaccination would prevent cataract and glaucoma in childhood. Congenital cataract, on the other hand, which is commonly seen in eastern Mediterranean countries, should be managed early for the prevention of amblyopia. It is evident that educational campaigns stressing the role of consanguinity, and the importance of early management of congenital glaucoma and cataract, may prevent more blindness in childhood.

\section{New technology and equipment}

The transfer of new technology and equipment from Western countries to eastern Mediterranean countries has been rapid in certain areas and may have contributed to complications. Training of staff should go in parallel with the sale of such technology. The transfer of skills and technology from the West should not be left to drug companies that have financial interest as a priority without proper training of individuals who are going to use the new technology. This has led to an increase in iatrogenic blindness and may have to be addressed by ophthalmic organisations. These companies should have the moral commitment to advertise and sell their products with proper continuing medical educational campaigns for the transfer of skills to the area. Continuing medical education (CME) for health workers in ophthalmology is critical in the prevention and cure of blindness. This type of activity has been carried out on a limited basis and mostly organised and sponsored by organisations, hospitals, or individuals. CME is either lacking or limited in many countries; and in some it is driven by financial interests of pharmaceutical companies. I have attended over 20 meetings on phacoemulsification and LASIK but none on the early prevention, diagnosis, and management of blinding ocular disorders.

Blindness remains a serious health problem and a major handicap in the eastern Mediterranean countries. Blindness causes considerable personal tragedy and places a socioeconomic burden on the individual and his society. Community based prevalence surveys remain the best means for generating a biased free estimate of the magnitude of the problem. The majority of the causes of blindness in eastern Mediterranean countries are either curable or preventable.

The ophthalmic communities of the eastern Mediterranean countries should work together and be committed to initiate, stimulate, and intensify research effort in ophthalmology to address blinding eye diseases in the eastern Mediterranean countries with an ultimate goal to diagnose and treat blinding diseases.

The productivity of the visually impaired person constitutes a major socioeconomic handicap. Blinding eye diseases remain a major public health problem in many developing countries. The prevention of such diseases is much less expensive than caring for those who are blind in these communities. Policies for the prevention of blindness are crucial to design effective intervention and prevention programmes. ${ }^{22}$ These programmes are at different levels - governmental, organisational, and individual.

\section{Requirements for improving eye care}

The major needs for ophthalmic care in many eastern Mediterranean countries include (1) recognition and referral of age related cataract, (2) maintenance of acceptable standards for ocular surgery to prevent operative complications, (3) early identification and treatment of ocular surface infections such as trachoma and corneal ulcers, (4) identification of patients with lid deformities and dry eye for appropriate surgical correction and medical treatment, (5) proper management of eye disorders at the primary care level, (6) early detection and continuous management of increased intraocular pressure and glaucoma, (7) public education for the prevention of genetically 
determined blinding diseases and prevention of trauma in the playground and at the industrial level.

Primary healthcare centres in many countries lack the essentials of ophthalmic care. Public health outpatient clinics are usually well staffed by general practitioners and nurses, but many of those are unfamiliar with common eye problems and how to treat them. ${ }^{23-26}$ In order not to overload the specialty services, a large proportion of routine eyecare tasks must be performed by non-ophthalmologists. This is especially true for effective action against a disease such as trachoma, where treatment is simple and there is high need for widespread recognition of the disease and effective patient education. Trachoma is easy to treat and complications leading to loss of vision can be avoided. Nutritional blindness, such as vitamin A deficiency, remains an important cause of blindness that can be prevented in some eastern Mediterranean countries. ${ }^{27}$ In order to be realistic, the existing resources in the healthcare system should be well utilised and campaigns for continuing medical education of general practitioners and nurses are highly desirable to recognise and treat eye diseases and to refer those that require an ophthalmologist's care.

A central eye bank with a proper distribution network of corneal tissue should be established in the eastern Mediterranean countries where ophthalmologists will be able to receive corneal tissues in a safe and effective manner. This would help in the intervention and control of avoidable blindness from corneal opacities. Health workers, general practitioners, and physicians working in the delivery of eye care should be informed about the importance, early management, and prevention of corneal opacities.

Public education campaigns should also be developed in order to encourage the use of protective sunglasses, minimise industrial hazards, and warn against the purchase of dangerous games for children. Furthermore, regulations for the use of seat belts and infant seats should be developed and implemented. The public should be warned of the danger of using folk remedies that may cause conjunctival cicatrisation and corneal opacities.

1 Thylefors B, Negrel AD, Pararajasegaram R, et al. Global data on blindness. Bull World Health Organ 1995;73:11521.

2 Thylefors B, Negrel AD, Pararajasegaram R, et al. Available data on blindness (Update 1994). Ophthalmic Epidemiol 1995;2:5-39.

3 Hosni FA. Survey of major blinding conditions in Qatar. Ophthalmologica 1977;175:215-21.

4 Hegab SM, Omin OM. Defective vision among Kuwaiti students. F Pediatr Ophthalmol Strabismus 1982;19:146-51. Hamdan Y. Survey on blindness in Kuwait. Bull Ophthalmol Soc Egypt 1968;61:417-20.

6 Tabbara KF, Badr I. Changing pattern of childhood blindness in Saudi Arabia. Br F Ophthalmol 1985;69:31215.

7 Al Salem M. Rawaçhdeh N. Pattern of childhood blindness and partial sight among Jordanians in two generation. $\mathcal{f}$ Pediatr Ophthalmol Strabismus 1992;29:361-5.

8 Mansour AM, Kassak K, Chaya M, et al. National survey of Mansour AM, Kassak K, Chaya M, et al. National survey of
blindness and low vision in Lebanon. Br $\mathcal{f}$ Ophthalmol 1997;81:905-6.

9 Tabbara KF, Baghdassarian SA. Childhood blindness in Tabbara KF, Baghdassarian SA. Childhood
Lebanon. Am $\mathcal{f}$ Ophthalmol 1975;79:827-30.

10 Ayed S, Negrel AD, Nabli M, et al. Prevalence and causes of blindness in the Tunisian Republic. Results of a national survey conducted in 1993. Sante 1998;8:275-82.

11 Ayed S, Daghfous F, Guermazi K, et al. Causes of blindness in Tunisian children. Rev Int Trach Pathol Ocul Trop Subtrop Sante Publique 1991;68:123-8.

12 Tabbara KF, Ross-Degnan D. Blindness in Saudi Arabia. ҒAMA 1986;255:3378-84.

13 Sommer A. Blindness in Saudi Arabia. FAMA 1986;255: 3405-6.

14 Baghdassarian SA, Tabbara KF. Childhood blindness in Lebanon. Am f Ophthalmol 1975;79:827-30.

15 Tabbara KF, Al Omar OM. Trachoma in Saudi Arabia. Ophthalmic Epidemiol 1997;4:127-40.

16 Penna EP, Tabbara KF. Oxybuprocaine keratopathy: a preventable disease. Br F Ophthalmol 1986;70:202-4

17 Tabbara KF. Kermes-induced cicatrisation of the conjunctiva. Ann Saudi Med 1986;6:233-6.

18 Tabbara KF. Cautery, folk remedies, and magic. Ann Saudi Med 1989;9:433-4.

19 Tabbara KF, El-Sheikh HF, Aabed B. Extended wear contact lens related bacterial keratitis. $\mathrm{Br} \mathcal{F}$ Ophthalmol 2000;84:327-8

20 Mussafar W, Khan MD, Akbar MK, et al. Mine blast injuries: ocular a and social aspects. Brf Ophthalmol 2000; 84:626-30.

21 Tabbara KF. Ocular complications of vernal keratoconjunctivitis. Can Ophthalmol 1999;34:88-92.

22 Tabbara KF. Sight and farsight in blindness. Saudi 7 Ophthalmol 1992;6:57-8.

23 Jebejian R. Glaucoma, a current major problem among the causes of blindness in Syria. Rev Int Trach Pathol Ocul Trop Subtrop Sante Publique 1985;62:139-44.

24 Dawson CR, Daghfous T, Messadi M, et al. Severe endemic trachoma in Tunisia. Br f Ophthalmol 1976;60:245-52.

25 Courtright P, Sheppard J, Schachter J, et al. Trachoma and blindness in the Nile Delta: current patterns and projections for rural Egyptian population. Br $\mathcal{F}$ Ophthalmol 1989;73:536-40.

26 Jones BR. The prevention of blindness from trachoma. Trans Ophthalmol Soc UK 1975;95:16-33.

27 Rosen DS, Al Sharif Z, Bashir M, et al. Vitamin A deficiency and xerophthalmia in western Yemen. Eur $\mathcal{f}$ Clin Nutr 1996;50:54-7. 